\title{
Variation of nonlocal irrigation in a subtidal benthic community
}

\author{
by Stefan Forster ${ }^{1}$, Arzhang Khalili ${ }^{2}$ and Jarmila Kitlar ${ }^{3}$
}

\begin{abstract}
Irrigation, the effect of the pumping activity by benthic infauna on pore water solute distribution and fluxes, may be represented by a nonlocal irrigation function, $\alpha$ (units: 1/time) in the general diagenetic equation. We derived $\alpha$ from the distribution of a solute tracer, bromide, during laboratory incubations of sediment cores containing their natural faunal community. Sediments were sampled on 4 occasions over a period of one year from a site at $30 \mathrm{~m}$ depth in the southern North Sea. Fitting an irrigation function exponentially decaying with depth, we arrived at $\alpha$-values ranging from 25 to $>200 \mathrm{yr}^{-1}$ at the sediment water interface and $\alpha<10$ at $16 \mathrm{~cm}$ depth. The importance of meaningful horizontal averaging was shown by contrasting our values with unreasonable high $\alpha$ based on inappropriate sampling. Variability of $\alpha$ between adjacent samples $(n=3-6)$ was as large as seasonal differences, and this fact underlines the necessity for cautious interpretation of data from single cores. No temperature effect on $\alpha$ was observed in the temperature range of $5-16^{\circ} \mathrm{C}$ since abundance of fauna and their behavior completely dominated the magnitude of $\alpha$. Nutrient fluxes associated with this nonlocal irrigation are highly variable on a spatial scale reflecting macrofauna heterogeneity. The irrigation flux reduces the relative importance of temperature as a factor on benthic-pelagic solute fluxes.
\end{abstract}

\section{Introduction}

Wherever the overlying water contains oxygen, benthic fauna capable of mechanical mixing of sediments, bioturbation, and pumping of water through burrows and tubes, (bio-) irrigation, inhabit the sediment. Solute transport in sediments may proceed as a random mixing process described by enhanced diffusion coefficients (Aller and Aller, 1992; Östlund and Hallberg, 1989) and some burrowing activity may in fact be well described as biodiffusion (Boudreau, 1997). More often the irrigation process results in threedimensional radial diffusion gradients associated with the spatial dwelling structures generated by the benthic inhabitants (Ziebis et al., 1996b). Consequences for solute distributions and fluxes from irrigation have been illustrated by Aller (1980) in his radial diffusion model. An alternative way of describing the process of solute exchange between

1. Baltic Sea Research Institute Warnemuende, Seestrasse 15, D-18119 Rostock, Germany. email: stefan.forster@io-warnemuende.de

2. Max-Planck-Institute for Marine Microbiology, Celsiusstr. 1, D-28359 Bremen, Germany.

3. Grunauzeile 4, D-24114, Kiel, Germany. 
overlying water and sediment, introduced by Emerson et al. (1984) and Boudreau (1984), assumes 'nonlocal,' instantaneous exchange of matter characterized by an exchange coefficient $\alpha$ (units: 1/time). Recent models of early diagenesis of shallow water sedimentary systems (Boudreau et al., 1998; Soetaert et al., 1996; van Cappellen and Wang, 1996) underline the importance of irrigation and the necessity of its inclusion into a coherent picture of the manifold complex interactions during early diagenesis. While a wide range of studies exist in which the overall effect of particle mixing by bioturbation is characterized through the mixing coefficient $D_{b}$ (compiled in Boudreau, 1998), the equivalent values on the coefficient for solute exchange, $\alpha$, are relatively scarce.

By evaluation of tracer concentration gradients in the sediment, the depth distribution of apparent sources and sinks has be simulated and quantified assuming an exponentially decaying nonlocal exchange function (Martin and Banta, 1992). In this contribution we apply this latter approach to samples from a North Sea sediment taken over the course of one year, adding to the comparatively scarce data in the literature. We present nonlocal exchange coefficients, derived from sediment microcosms incubated in the laboratory and including the natural abundant macrofauna. We discuss the primary factors for the variation of $\alpha$ throughout the year and compare nutrient fluxes associated with irrigation activity to diffusive fluxes.

\section{Methods}

\section{a. Site description and sampling}

Sediments were collected from a site at $35 \mathrm{~m}$ water depth at $54^{\circ} 01^{\prime} \mathrm{N} / 07^{\circ} 49^{\prime} \mathrm{E}$ in the German Bight, southern North Sea. The sediment consisted of a silty sand $(6 \% \mathrm{wt} \geq$ $250 \mu \mathrm{m} ; 52 \%$ wt $125-250 \mu \mathrm{m} ; 22 \%$ wt $250-63 \mu \mathrm{m} ; 20 \%$ wt $\leq 63 \mu \mathrm{m})$ and the benthic macrofauna has been described as a Nucula nitidosa assemblage (Salzwedel et al., 1985), representative of large parts of the North Sea (Duineveld et al., 1991). PSU averages $31 \pm$ 1 , and, since strong tidal mixing prevents density stratification of the water column in the Southern German Bight, the yearly temperature cycle of $14^{\circ} \mathrm{C}$ also affects the sediment.

Sediment was sampled using a box corer $(50 * 50 \mathrm{~cm})$ provided with 4 acrylic liners ( $20 \mathrm{~cm}$ inner diameter, $45 \mathrm{~cm}$ height). Upon retrieval, cores were kept aerated, in the dark, and at in situ temperature during transport and in the laboratory. Multicorer tubes $(10 \mathrm{~cm}$ inner diameter) were collected for tracer diffusion experiments and the determination of pore water solute content. Cores to be used in diffusion experiments were frozen at $-18^{\circ} \mathrm{C}$ for $40 \mathrm{~h}$ in order to kill the fauna and were subsequently thawed and incubated together with the larger sediment cores containing fauna at natural abundances.

Between 16 and 20 sediment cores were sampled at one occasion and cores were randomly taken from one or several subsequently retrieved box cores. Thus, adjacent cores used in this study were sampled on a horizontal scale between $20 \mathrm{~cm}$ within one haul and several meters between different box corer hauls.

On October 23, 1988 macrofauna were sieved ( $250 \mu \mathrm{m}$ mesh) from intervals of $0-5$, 
5-15 cm, and 15-25 cm sediment depth taken from 3 box corers (total area: $0.75 \mathrm{~m}^{2}$ ) and preserved in a formalin-depot solution (Brey, 1986). On all subsequent dates an interval from $0-15 \mathrm{~cm}$ was sieved and only values from this depth range are reported here. Observed individuals include Callianassa subterranea, which were hand-picked from their burrows that extend below the depth to which we sieved the sediment. The abundance of tube-building Owenia fusiformis, occurring in high numbers, was determined by sub sampling characteristic tubes from the three samples obtained in October 1988. These were pooled and a relation established between tube wet weight, tube length, and the number of individuals of $O$. fusiformis found in the tubes: there were 30 animals in $0.50 \mathrm{~g}$ tube material of $79.8 \mathrm{~cm}$ total tube length. This information was used to convert tube wet weight from the original samples into abundances.

\section{b. Experimental procedure}

After transport, cores were left to equilibrate under laboratory conditions for 2-3 days. For the determination of solute transport, $\mathrm{NaBr}$ was added to the overlying water as inert tracer (Aller, 1983; Dicke, 1986) and both the concentration decline in the water and its final distribution in the sediment pore water determined. A brine of $\mathrm{NaBr}$ was added to a final concentration of about $18 \mathrm{mM}$ (30-fold natural background) to the overlying water, stirred once, and the water agitated by a light stream of air bubbles during the whole experiment. We found the tracer to be homogeneously distributed throughout the water column after 15 minutes. Cores were thus incubated for a period of roughly 4 days, but exact duration noted and used in the simulation described below.

Cores were sectioned at intervals of $0.5 \mathrm{~cm}$ to $3 \mathrm{~cm}$ depth and $1.0 \mathrm{~cm}$ below, typically to $14 \mathrm{~cm}$ sediment depth. The outermost ring of sediment, $1 \mathrm{~cm}$ wide, was cut off and discarded using a stencil. Thus, we avoided artifacts owing to wall effects (Chant and Cornett, 1991). Each sediment layer was thoroughly mixed in a beaker using spatulas. Pore water was separated from $12 \mathrm{~cm}^{3}$ subsamples of wet sediment by centrifugation $(2000 \mathrm{~g})$ in cups similar to the ones described by Saager et al. (1990). Porosity was calculated for each depth interval from wet and dry weights $\left(24\right.$ hours at $\left.60^{\circ} \mathrm{C}\right)$ of triplicate $5 \mathrm{~cm}^{3}$ samples. Large fauna or burrows found during slicing were noted.

On one occasion pore waters from within $1 \mathrm{~cm}$ around burrows of $L$. conchilega and $C$. subterranea were sampled intentionally, exploring the differences between average $\mathrm{Br}^{-}$-concentrations (see above) and local concentrations close to burrows. Sediment was sampled with a spatula to $1 \mathrm{~cm}$ depth within a $2.6 \mathrm{~cm}$ circle of tubing positioned around the tube/burrow with a diameter of $6-8 \mathrm{~mm}$.

For comparison we re-analyzed data published earlier (Forster et al., 1995). Analytical procedure in obtaining the data was the same. In this asphyxiation experiment, sediment cores had been exposed to hypoxic conditions (25\% saturation; $67 \mu \mathrm{M} \mathrm{O}_{2}$ ) for 15 days followed by a reoxygenation phase in fully oxygen-saturated water. 


\section{c. Analytical}

Bromide was analyzed by titration according to Kremling (1983). The precision was 7\% at natural seawater background levels $(\sim 0.8 \mathrm{mM})$ and decreased to $1 \%$ at higher concentrations above $5 \mathrm{mM}$. Recovery of tracer from the pore water accounted for $70-90 \%$ of tracer lost from the overlying water during the experiment. We only report excess $\mathrm{Br}^{-}$concentrations here above the natural background.

All nutrients were analyzed after appropriate dilution with Milli-Q water according to Grasshoff et al. (1983). Photometric determination of ammonia was performed after reaction with indophenol. Nitrite was detected following the transformation into an amino-azo-compound, and dissolved inorganic phosphate and silica following the reaction into a heteropolyacid.

\section{d. Mathematical modelling of bioirrigation}

Following Martin and Banta (1992), the transport equation to determine the distribution of the ion tracer may be written as

$$
\frac{\partial C(z)}{\partial t}=\frac{1}{\phi(z)} \frac{\partial}{\partial z}\left[D_{s} \phi(z) \frac{\partial C(z, t)}{\partial z}\right]-\alpha(z, t)[C(z, t)-C(0, t)]
$$

with

$$
\begin{gathered}
\phi(z)=a_{k}+k_{1} e^{-k_{2} z} \\
D_{s}=\frac{D_{0}}{1-b \ln (\phi)} \\
\alpha(z)=\alpha_{0} e^{-\alpha_{1} z} .
\end{gathered}
$$

In the above equations, $C$ is the concentration (units: $\mathrm{mM}), z(\mathrm{~cm})$ and $t(d)$ are the depth and time coordinates, $\phi$ is the depth dependent porosity, $D_{s}\left(\mathrm{~cm}^{2} \mathrm{~d}^{-1}\right)$ is the diffusivity of the ion tracer in the sediment, $D_{0}\left(\mathrm{~cm}^{2} \mathrm{~d}^{-1}\right)$ is the diffusivity of the ion tracer in seawater, and $\alpha\left(\mathrm{d}^{-1}\right)$ is the so-called nonlocal irrigation function. Furthermore, $a_{k}, k_{1}, k_{2}, b, \alpha_{0}$ and $\alpha_{1}$ are free parameters.

Initial and boundary conditions are as follows. It is assumed that the concentration at the sediment-water interface is equal to the overlying water concentration,

$$
C(z=0, t \geq 0)=C_{\text {olw }} .
$$

At the bottom an additional boundary condition in the form of a concentration gradient is implemented:

$$
\frac{\partial C\left(z=z_{\max }, t>0\right)}{\partial z}=0 .
$$


Since the overlying water volume taken for calculations is limited (water layer thickness $h$ ), we have to account for a temporal decrease in $C_{\text {olw }}$ caused by the transfer of ion tracer into the pore water. This is taken care of by integrating the concentration profile over the sediment depth (Martin and Banta, 1992):

$$
C(t>0)=C_{\text {olw }}(t=0)-\frac{1}{h} \int_{0}^{z_{\max }} \phi C(z, t) d z .
$$

Note that this integral has to be solved for each time step $\Delta t$ in order to update the boundary condition (5).

The aim of the numerical simulation is to determine the irrigation rates of sediments based on experimental results. Porosity and concentration profiles are available from measurements. We first find the porosity parameters given in (2) directly from using a common nonlinear least square fit (Press et al., 1992). Next, an arbitrary set of values are taken for $\alpha_{0}, \alpha_{1}$ in (4) to obtain a depth dependent irrigation function $\alpha$. Using these inputs along with the boundary conditions (Eqs. 5-7), concentration profiles are obtained by solving the differential equation (1), and the results are compared with those obtained in experiments.

With the help of a least square fit, the irrigation parameters are modified systematically until a minimum deviation between the numerical and experimental data is achieved. The least square method employed belongs to the family of so-called 'full-Newtonian-type,' and are considered to be more robust than Levenberg-Marquardt, but more complex. Details of this method can be found in a paper by (Dennis et al., 1981), and available in MINIPACK software package (Moré et al., 1980).

For the solution of (1), the Crank-Nicholson method (Crank and Nicholson, 1947) is used. The integral given in (7) is solved using a modified Simpson's rule (Press et al., 1992). Special attention has to be given to the use of the Crank-Nicholson method in order to avoid problems due to 'stiffness.' We have carried out two different finite difference techniques to ensure the convergence and the stability of the results presented. The first one departed from constant (equi-distant) meshes, and the second one used variable mesh sizes. Constant mesh sizes were achieved by dividing the entire depth by a constant number $N$ (varied between $10^{2}$ and $10^{4}$ ) in different numerical experiments in connection with the time step, $\Delta t$ (varied between $10^{-2}$ and $10^{-4}$ ) to satisfy the Courant-Friedrichs-Lewy (or the CFL) stability criterion. It was found that sufficiently accurate results can be obtained with $N=100$ and a $\Delta t=10^{-3}$. Variable meshes were generated using transformation functions that produced fine grids near the water-sediment interface $(z=0)$, and coarse grids inside the computational domain with $N=100$ and $\Delta t=10^{-3}$. The results of both techniques were similar, and fulfilled the accuracy requirements of the convergence criterion avoiding 'stiffness.' 


\section{e. Tortuosity correction}

For an initial simulation of tracer distribution in the sediment we chose the case of molecular diffusive transport only (diffusion experiment). We used the tortuosity-porosity relation given by the modified Weissberg equation (Boudreau, 1997; Weissberg, 1963)

$$
\theta^{2}=1-b \ln (\phi)
$$

Throughout all calculations including the diffusion experiments we used $b=3.1$. This value was chosen in order to successfully model tracer distributions derived only through the process of molecular diffusion, with no irrigation present.

Statistical testing of the differences of mean $\alpha_{0}$ and $\alpha_{1}$ for different seasons was performed through ANOVA. The correlations of mean $\alpha_{0}$ and $\alpha_{1}$ were tested against temperature $(n=4)$ and abundance of fauna $(n=3)$ using simple linear regression analysis.

\section{Results}

\section{a. Simulation close to the interface}

With the simulation procedure used we were able to reproduce tracer distributions obtained by diffusion using an irrigation coefficient essentially equal to 0 . The simulation of the transport process starts by the fitting of porosity data measured at $5 \mathrm{~mm}$ intervals. The shape of this function compares favorably to the porosity gradient close to the sediment-water interface, where we encountered porosities between 0.9 and 0.6 as measured at $1 \mathrm{~mm}$ spatial resolution (Fig. 1). Slightly higher porosities in the deeper data are likely due to local heterogeneity, since shallow samples were taken from a different sediment core.

In our initial simulations of the diffusion-only experiments, we observed that with $D_{s}$ for $\mathrm{Br}^{-}$calculated according to Archie's Law (Ullman and Aller, 1982) or with $b=2$ in (8) (Boudreau, 1997), the tracer concentrations were too high close to the sediment-water interface, and lower than measured at depths below $1 \mathrm{~cm}$, i.e. implying that $\alpha_{0}$ and $\alpha_{1}>0$. Meiofauna, which could potentially enhancing diffusion close to the interface, had been killed by the freezing procedure, and microscopy of the sediment samples confirmed their absence. Uncertainty in $D_{0}$, i.e. $\pm 8 \%$ (Li and Gregory, 1974) is an unlikely cause for the observed discrepancy. We thus conclude that the lack of an exact tortuosity-porosity relation in our sediments was a key factor. Simulating each diffusion data set separately with a target of $\alpha_{0} \leq 0.01 \mathrm{yr}^{-1}$ and $\alpha_{1}<10^{-6} \mathrm{~cm}^{-1}$ or essentially equivalent to 0 (i.e. no irrigation), we found that $b$ differed for every diffusion-only core $(3.1,2.1,1.6)$.

In principle larger $b$ coefficients are associated with a smaller diffusive contribution to the total flux in the simulation and may, thus, result in a higher irrigation constant necessary to meet the observed tracer distribution. Since we cannot determine $b$ for the experiments with irrigation activity, exactly how much the tortuosity-porosity relations in different sediment cores affect fluxes remains an open question. An insert in Figure 2 
porosity ( $\mathrm{vol} / \mathrm{vol})$

bromide (mM)

bromide (mM)
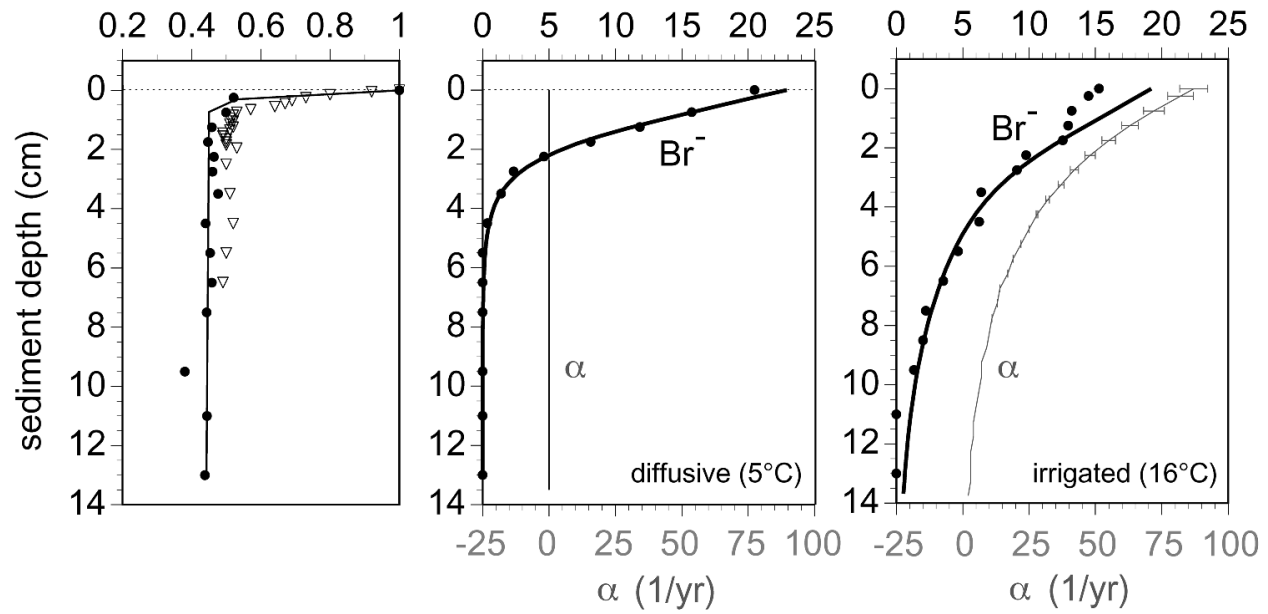

Figure 1. Example data set for the determination of the nonlocal exchange function $\alpha$. Left: Porosity data sampled at coarse resolution and fit by exponential function according to Eq. (2) (dots; line). Data sampled from a parallel core at higher resolution (triangles, no fitting) support the existence of a steep gradient at the sediment-water interface. Middle: the tracer distribution (dots) in a diffusion-only experiment is reproduced by modeling (fat line) without irrigation (thin line; $\alpha \leq$ $0.01 \mathrm{yr}^{-1}$ on lower abscissa). Right: With benthic infauna present, simulation of the tracer distribution yields $2<\alpha<85 \mathrm{yr}^{-1}$. Horizontal bars depicted on the $\alpha$-profile indicate an estimate of deviation possible, in case that the calculation had been performed using a different ' $b$ ' in Eq. 8 (see text for details).

depicts $D_{s}$ as a function of porosity both for Archie's Law (Ullman and Aller, 1982) and (8) with $b=2$ and $b=3.1$. The latter relation yields lowest diffusive fluxes close to the sediment-water interface.

We estimate the potential deviation in irrigation function associated with the range of $b$ observed in the diffusion cores as follows. We used $b=3.1$ in all the simulations including the two remaining diffusion experiments. For a typical tracer distribution with active irrigation (August $16^{\circ} \mathrm{C}$; core A1), we additionally calculated $\alpha$-values using $b=$ 1.6. The distance between both $\alpha$-values indicates how much the unknown tortuosityrelation affects calculated $\alpha$ in our simulations (Fig. 1). Variability is of the order of $6 \%$ or $\pm 4 \mathrm{yr}^{-1}$ at $z=0$ to $<1 \%$ or $\pm 0.5 \mathrm{yr}^{-1}$ at $6 \mathrm{~cm}$ depth. Compared to other sources of variability these deviations are minor and thus acceptable for the scope of this investigation. We maintain, though, that close to the interface, tortuosity, which is probably not well accounted for in the present formulae, exerts a relatively strong influence on fluxes.

For comparison with the values reported by Martin and Banta (1992) we also calculated $\alpha_{0}$ and $\alpha_{1}$ using Archie's law $\left(D_{s}=D_{0} \phi^{2}\right)$. The average effect was to reduce $\alpha_{0}$ and $\alpha_{1}$ by factors 0.90 and $0.94,(n=23)$. While $\alpha_{0}$ is lower, the smaller attenuation with depth translates into roughly the same $\alpha_{0-10}$ (integration 0-10 cm depth) as if Archie's Law were 

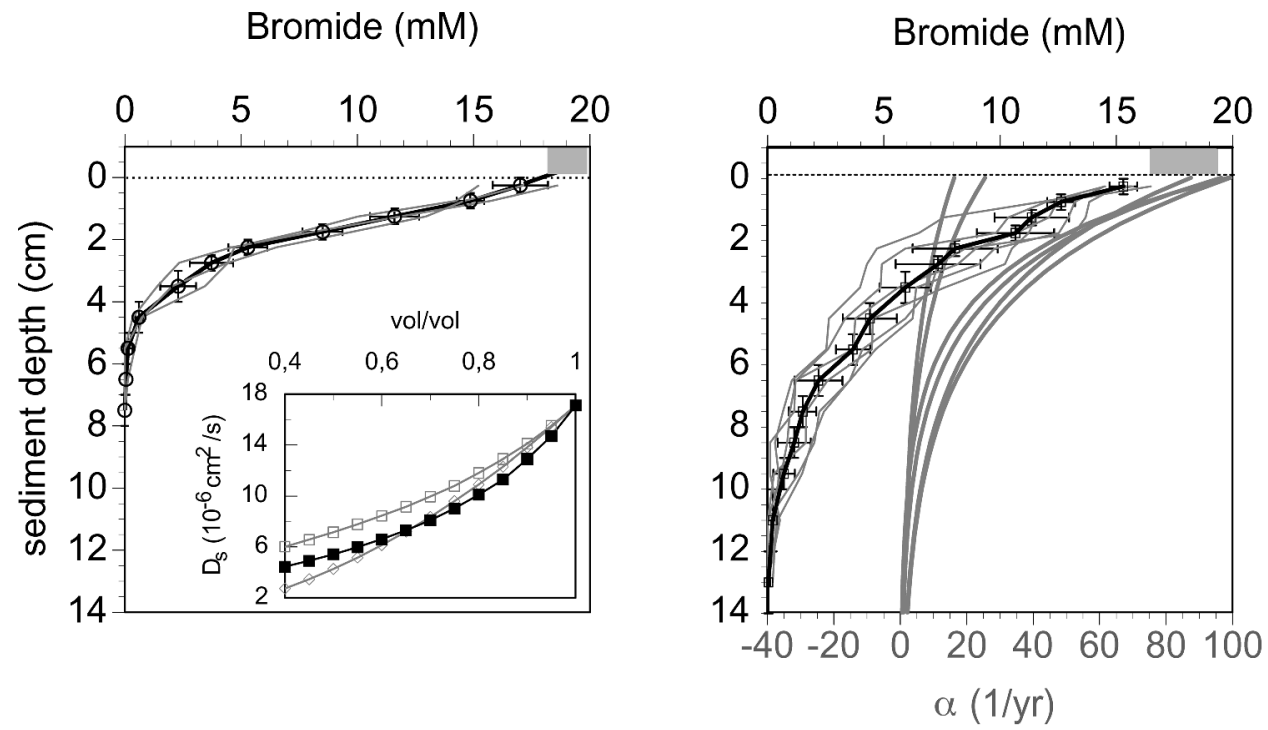

Figure 2. Variability of tracer data and of $\alpha$. Tracer distributions are given in thin gray lines for three replicate sediment cores with only molecular diffusive transport acting (left), and 6 parallel cores (right) where additionally bioirrigation was effective. In each case the average concentrations \pm 1 s.d. (upper abscissa) are given in black. Resulting distributions of $\alpha$ with depth vary considerably among parallel cores (heavy gray lines; lower abscissa). Hatched areas indicate the range of $\mathrm{Br}^{-}$-concentrationsin the overlying water at the end of the experiments. Insert: Empirical relations of the sediment diffusion coefficient for bromide, $D_{s}$, and porosity. Archie's Law (diamonds; Berner, 1980), was not appropriate to fit our diffusion-only experiment data. Instead, the Weissberg relation with exponent $b=3.1$ (black squares) was used. The Weissberg relation with $b=2$ is given for comparison (open squares). See text for details.

used. So while the depth-distribution of $\alpha$ is changed by the computation method used, the integrated $\alpha$-value in the surface layer remains the same.

\section{b. Tracer distribution}

The depth-distribution of tracer was similar for all cores taken at the four sampling occasion. Variation among six replicate cores sampled in August (Fig. 2) has a standard error increasing from $4 \%$ at the sediment-water interface to $100 \%$ at $11 \mathrm{~cm}$ sediment depth. This range is typical for the other sampling dates (see below) as well, although variation in some data is higher (e.g. Fig. 3, February $1.25 \mathrm{~cm}$ ). With live benthic fauna present in the sediment cores, tracer reached sediment depths between 10 and $16 \mathrm{~cm}$ as opposed to only 6-7 cm with diffusive transport (Fig. 2, 3). In our batch type experiment with a limited source of tracer supply from above, the flux results in depletion of tracer in the overlying water and upper sediment layers relative to the diffusion control experiments.

Overall, the tracer distributions, both individual and average concentrations, did not differ significantly among the four sampling dates over the course of a year (Fig. 3). No 
Bromide (mM)
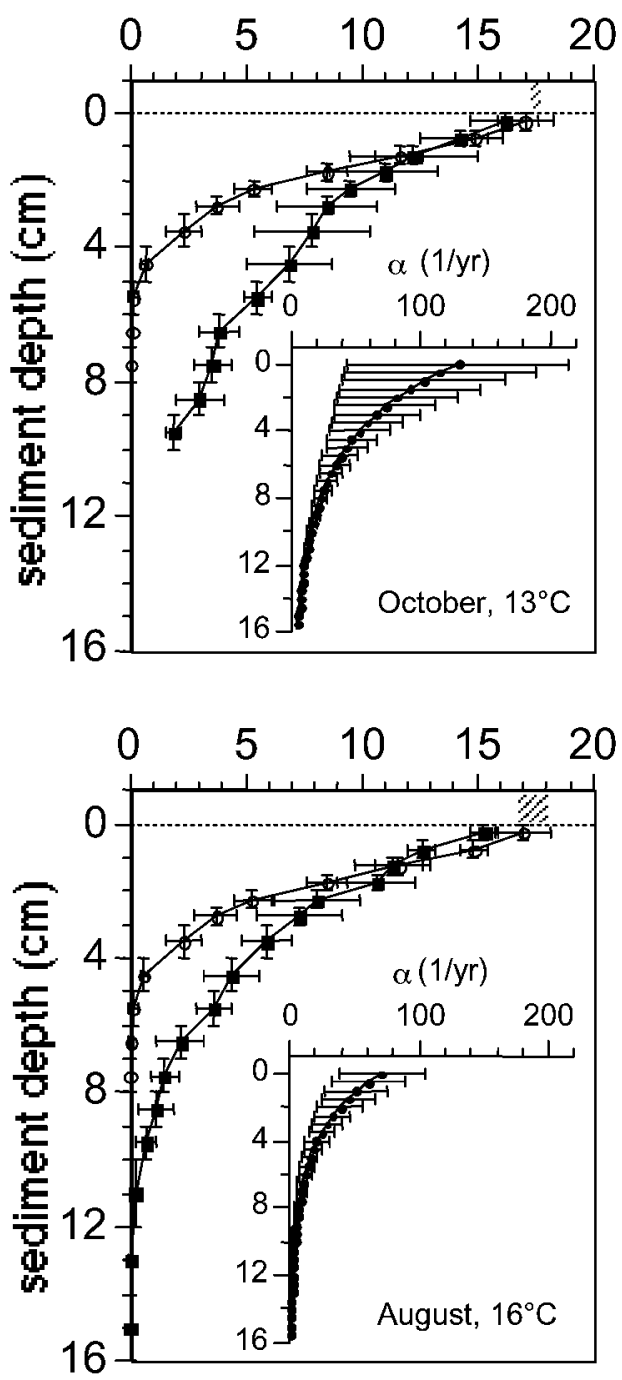

Bromide (mM)
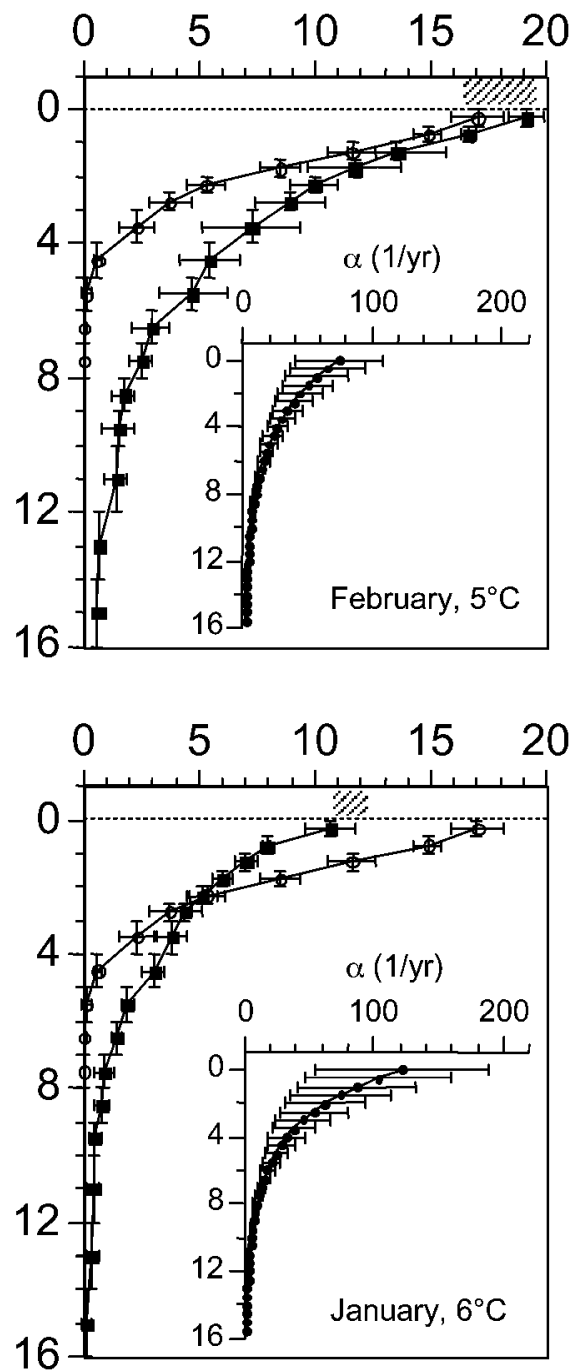

Figure 3. Averages \pm 1 s.d. of tracer distribution and resulting $\alpha$ (inserts) during the course of a year. $N=3$ for all times except August, when $n=6$. The diffusion experiment data given for comparison are the same in each graph. Hatched areas indicate the range of $\mathrm{Br}^{-}$-concentrationsin the overlying water at the end of the experiments.

appreciable differences were found between average concentrations among sampling times. In the January incubations $\left(6^{\circ} \mathrm{C}\right)$, the standard deviation was generally lower over all depths than in the other incubations. Conversely, February incubations $\left(5^{\circ} \mathrm{C}\right)$ showed stronger variation among bromide profiles. Concentrations in the overlying water affect the 
curvature of the profiles, as seen in the January incubation. Penetration depth of tracer, though, is not reduced: bromide reaches a sediment depth of $13 \mathrm{~cm}$ as opposed to only $6 \mathrm{~cm}$ with diffusive transport.

\section{c. Irrigation constants}

With animals present, the observed concentrations were simulated using molecular diffusion plus the nonlocal exchange contribution in (1). Irrigation constants $\alpha_{0}$ and $\alpha_{1}$ were fitted as part of the simulation process, and the results are given in Table 1. In Figure 3 , inserts depict depth distributions of $\alpha$, calculated according to (4). Values at the sediment surface range from $259 \mathrm{yr}^{-1}$ to $21 \mathrm{yr}^{-1}$ and decay to between $2 \mathrm{yr}^{-1}$ and $17 \mathrm{yr}^{-1}$ at $10 \mathrm{~cm}$ depth. At $16 \mathrm{~cm}$, the maximum depth to which tracer concentrations were determined, $\alpha$ was between $6.8 \mathrm{yr}^{-1}$ and $0.3 \mathrm{yr}^{-1}$.

Transport of tracer by bioirrigation appeared to reach a depth of $16 \mathrm{~cm}$. Highest variability in $\alpha$ was found in the upper $10 \mathrm{~cm}$ of the sediment. Here, high surface values, $\alpha_{0}$, were often associated with a faster attenuation with depth, i.e. large $\alpha_{1}$. Means of $\alpha_{0}$ and $\alpha_{1}$ for all four sampling dates are not significantly different from one another (ANOVA; $p=0.54, n=3$ and $0.41, n=3$ ). Similarly, there is no statistically significant difference in the means of irrigation constants when the data from experimental hypoxia and the subsequent reoxygenation phase are included $(n=6$; Table 1).

For better comparison of the overall irrigation intensity we averaged $\alpha$ over depth intervals $0-5,5-10,10-15,15-20$, and 20-25 cm (Martin and Banta, 1992). It can be seen from Table 2 that there is a large degree of variability in $\alpha$ for every depth interval (coefficients of variance 30-60\%). This is also evident in Figure 2, depicting functions $\alpha$ calculated from six pairs of $\alpha_{0}, \alpha_{1}$ constants from Table 1. While four cases of six form a cluster of very similar $\alpha$-distributions $\left(85<\alpha_{0}<100\right)$, two sediment cores have markedly lower irrigation constants, especially in the upper sediment layers $\left(\alpha_{0}<25\right)$. Values converge below $8 \mathrm{~cm}$ sediment depth. While the overall magnitude of $\alpha$ varies greatly among replicates, differences between seasons (temperature) are not detectable. The standard deviations of averages as seen in the inserts of Figure 3, overlap at all sampling dates. With the exception of the profile from October 1988, O1, $\alpha$-distributions are similar for temperatures between $5^{\circ} \mathrm{C}$ and $16^{\circ} \mathrm{C}$, i.e. January versus August. Incubation $\mathrm{O} 1$ resulted in the highest $\alpha$-values of the simulations.

We also obtained high $\alpha$-values using data from the asphyxiation experiment reported earlier (Forster et al., 1995). In this case $\alpha$-values increased as a consequence of reduced oxygen concentration in the overlying water and consequent hyperventilation of the benthic infauna (Fig. 4). With two exceptions only, $\alpha_{0}$ was $>100 \mathrm{yr}^{-1}$ at the sedimentwater interface in the hypoxic phase and reoxygenation phase of the experiment. This led to a doubling of $\alpha_{\mathrm{O}-5_{5}}$ relative to fully oxic conditions. The hypoxic reaction also surpassed any other seasonal result, with the exception of O1. Furthermore, both under hypoxic conditions and in October, we observed average $\alpha_{15-20}>3$ and average $\alpha_{20-25}>0$, in contrast to other seasons, when values at these depths remained $<1$ (Fig. 4). 


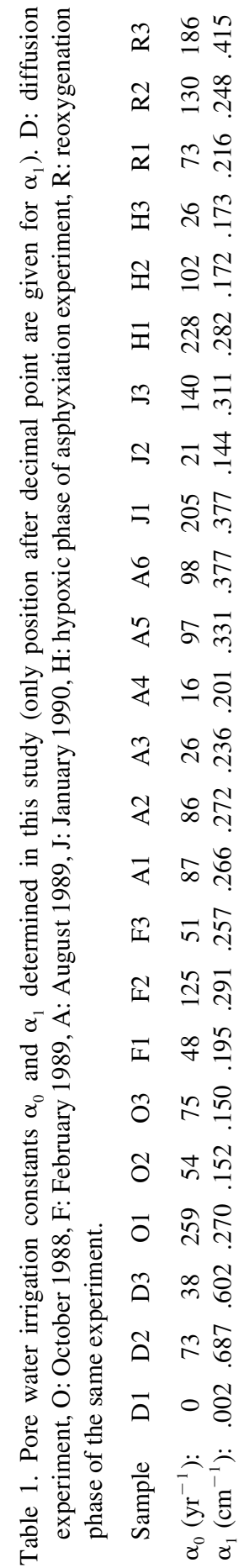


Table 2. Comparison of $\alpha$-values compiled and partially recalculated from different literature sources. When feasible, values were calculated from irrigation constants $\alpha_{0}$ and $\alpha_{1}$ and averaged over consecutive $5 \mathrm{~cm}$ intervals into the sediment. Otherwise $\alpha$ are given for the corresponding depth interval as given by the authors.

\begin{tabular}{|c|c|c|c|c|c|c|c|}
\hline Location & $\begin{array}{c}\alpha\left(\mathrm{yr}^{-1}\right) \\
\text { mean } \pm \mathrm{sd}\end{array}$ & $\begin{array}{l}\text { Range } \\
\left(\mathrm{yr}^{-1}\right)\end{array}$ & $n$ & $\begin{array}{l}\text { Depth } \\
\text { interval } \\
(\mathrm{cm})\end{array}$ & $\begin{array}{c}\text { Water } \\
\text { depth }(\mathrm{m})\end{array}$ & Solute & Source \\
\hline $\begin{array}{l}\text { Pacific, San Francisco } \\
\text { Bay }\end{array}$ & $36^{\mathrm{a}}$ & n.d. & 7 & $0-30$ & $4-14$ & & (1) \\
\hline Pacific, Pudget Sound & n.d. & $3-15^{\mathrm{b}}$ & 3 & $0-20$ & 15 & ${ }^{3} \mathrm{H}$ and $\mathrm{Si}(\mathrm{OH})_{4}$ & (2) \\
\hline $\begin{array}{l}\text { Washington continental } \\
\text { shelf }\end{array}$ & $51 \pm 30^{c}$ & $17-88$ & 6 & $2-10$ & 86 & $\mathrm{SO}_{4}^{2-}$ and $\mathrm{Ra}_{\mathrm{eq}}{ }^{\mathrm{d}}$ & (3) \\
\hline & $18 \pm 15$ & $0-36$ & & $10-30$ & & & \\
\hline North Sea, Skagerrak & $\begin{array}{c}110^{\mathrm{e}} \\
27 \\
7 \\
2 \\
0.4\end{array}$ & n.d. & - & $\begin{array}{c}0-5 \\
5-10 \\
10-15 \\
15-20 \\
20-25\end{array}$ & 190 & mainly $\mathrm{NH}_{4}^{+}$ & (4) \\
\hline Atlantic, Buzzard Bay & $\begin{array}{l}31 \pm 29 \\
10 \pm 2 \\
10 \pm 2\end{array}$ & $\begin{array}{l}0-70 \\
8-12 \\
8-12\end{array}$ & $4^{\mathrm{f}}$ & $\begin{array}{c}0-5 \\
5-10 \\
10-15\end{array}$ & 15 & $\mathrm{Br}^{-}$and $\mathrm{Ra}_{\mathrm{eq}}{ }^{\mathrm{d}}$ & (5) \\
\hline Baltic Sea, Kiel Bight & $\begin{array}{l}43 \pm 46 \\
52 \pm 39\end{array}$ & $\begin{array}{r}10-142 \\
7-128\end{array}$ & $\begin{array}{l}7^{\mathrm{g}} \\
8\end{array}$ & $\begin{array}{l}0-5 \\
5-10\end{array}$ & 19,28 & $\mathrm{Cl}^{-}$ & (6) \\
\hline Southern North Sea & $\begin{array}{c}50 \pm 34 \\
13 \pm 8 \\
4 \pm 3 \\
1 \pm 2 \\
<1\end{array}$ & $\begin{array}{c}10-141 \\
4-37 \\
1-12 \\
0-6 \\
0-3\end{array}$ & 15 & $\begin{array}{c}0-5 \\
5-10 \\
10-15 \\
15-20 \\
20-25\end{array}$ & 30 & $\mathrm{Br}^{-}$ & (7) \\
\hline Induced hypoxia & $67 \pm 35$ & $18-122$ & 3 & $0-5$ & 30 & $\mathrm{Br}^{-}$ & (7) \\
\hline
\end{tabular}

(1) Hammond and Fuller, 1979; (2) Emerson et al., 1984; (3) Christensen et al., 1984; (4) van Cappellen and Wang, 1996; (5) Martin and Banta, 1992; (6) Schlüter et al., 2000; (7) this study.

${ }^{\text {a }}$ One single value reported; recalculated by Boudreau (1997).

${ }^{\mathrm{b}}$ Assuming irrigation as constant for the depth interval indicated.

${ }^{\mathrm{c}}$ Values from Table 2 in Christensen et al. (1984) recalculatedaccording to $\alpha=B D_{s}$ (Boudreau, 1997).

${ }^{\mathrm{d}} \mathrm{Ra}_{\mathrm{eq}}:{ }^{222} \mathrm{Ra} /{ }^{226} \mathrm{Ra}$ disequilibrium.

${ }^{\mathrm{e}} \mathrm{Calculated}$ from the single best exponential irrigation function of a multicomponent diagenetic model (van Cappellen and Wang, 1996) fitting the extended data set of Canfield et al. (1993a,b).

${ }_{\mathrm{f}}^{\mathrm{f}}$ Averages of four unamended cores and depth intervals given by Martin and Banta (1992; Fig. 7).

${ }^{\mathrm{g}}$ From the total of 21 data (Schlüter et al., 2000; Fig. 13) 13 cases with negative irrigation coefficients and an outlier $\alpha=655 \mathrm{yr}^{-1}$ were removed.

\section{d. Burrows}

Investigation of bromide tracer distribution in the vicinity of burrows of $C$. subterranea and tubes of $L$. conchilega to $8 \mathrm{~cm}$ sediment depth show the impact of sampling location on $\alpha$. Concentrations scatter widely and no species-specific pattern is visible (insert in Fig. 5). 


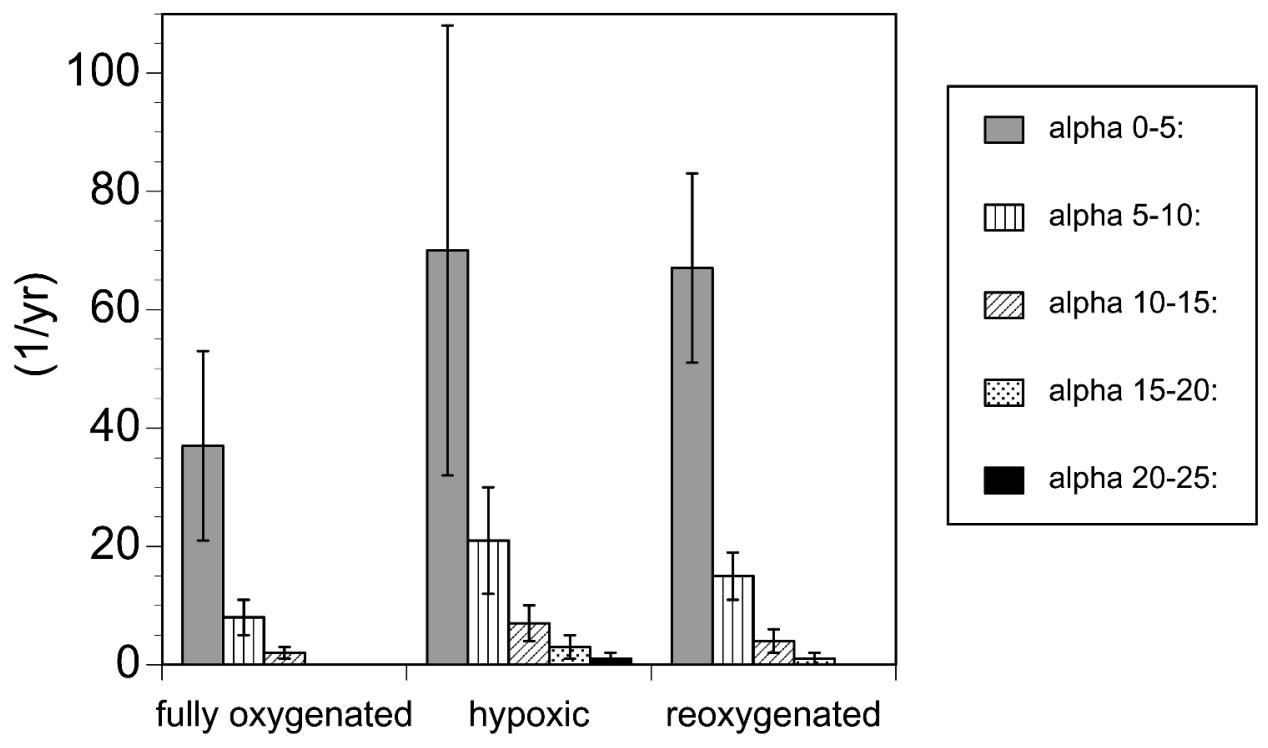

Figure 4. Hypoxia, reduced oxygen tension in the overlying water, induces more intense and deeper reaching irrigation. Results previously reported by Forster et al. (1995) are recalculated and expressed as $\alpha \pm 1$ s.d. for $5 \mathrm{~cm}$ depth intervals. Fully oxygenated conditions, equal to those in this contribution, were followed by 14 days hypoxia at $25 \% \mathrm{O}_{2}$ saturation, and an $\alpha$-determination 4 days into the reoxygenated phase, where normal conditions were reestablished in the water phase.

The use of a 1-D nonlocal model representation of irrigation is only meaningful if related to horizontally (radially) averaged concentrations (Boudreau, 1984; Emerson et al., 1984). In violation of this, sampling in close proximity to burrows results in $\alpha(n=15)$ approximately twice the average of all seasonal measurements, in $\alpha_{0} \sim$ three times the 'real' $\alpha_{0}$ based on average concentrations, and in slower attenuation with depth of the irrigation function. Thus, $\alpha$ from burrow concentrations depicted in Figure 5 are unreliably high.

\section{e. Relation of $\alpha$ to fauna and temperature}

Abundances of fauna determined from large sediment samples sieved on board displayed marked differences between October 1988 and all other cruises (Fig. 6; Table 3). Total numbers of species declined during the period investigated from 57 in October to 19 in August 1989. During the same period abundance fell from $7085 \mathrm{ind} \mathrm{m}^{-2}$ to 1083 ind $\mathrm{m}^{-2}$. Major groups in the benthic association did not change and polychaetes dominated the community by number on all occasions, with Owenia fusiformis dominant within this group. Contrary to the general trend there were three species with constant or increasing abundance, namely C. subterranea, O. albida, and L. conchilega (Table 3 ). Both irrigation constants $\alpha_{1}$ and $\alpha_{0}$ correlate with abundance of polychaetes and total abundance of fauna 


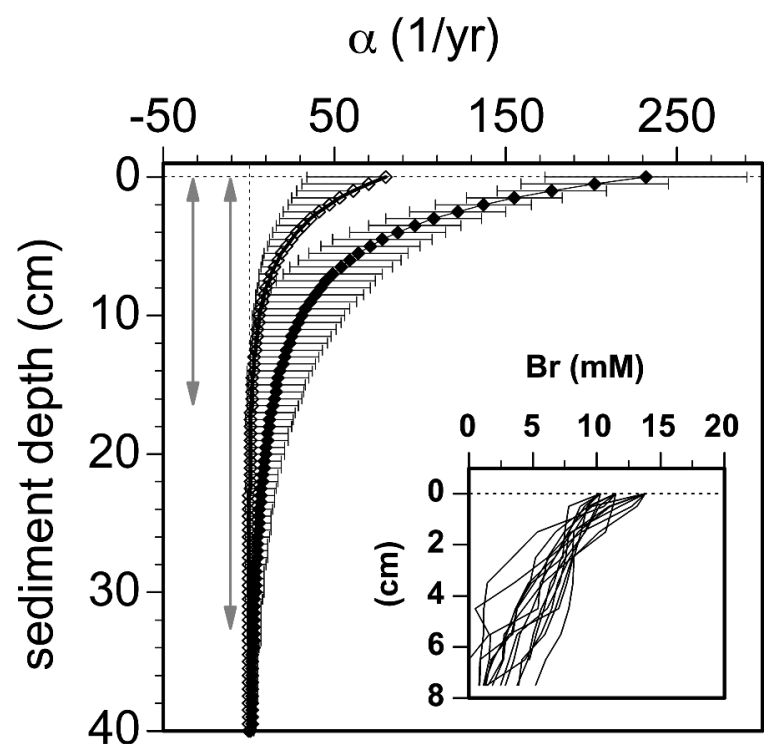

Figure 5. Impact of inappropriate sampling location on the irrigation function. While burrows have an effect on pore water chemistry below the $16 \mathrm{~cm}$ sediment depth, $\alpha$ based on sampling locally at burrows are meaningless in the sense that they are not calculated from horizontally averaged concentrations. Open symbols: $\alpha$ (average of all seasons \pm 1 s.d., $n=15$ ) from horizontally averaged tracer distribution as derived in our sampling routine including horizontal mixing of sediment within on layer. Closed symbols: $\alpha$ calculated from tracer concentrations determined within $2 \mathrm{~cm}$ horizontal distance off burrows of $C$. subterranea and L. conchilega $(n=15)$; the corresponding burrow tracer concentrations are depicted in the insert. Arrows indicate the depth range with $\alpha>1 \mathrm{yr}^{-1}$, derived from extrapolating the irrigation function (Eq. 4) to $40 \mathrm{~cm}$ sediment depth.

$\left(r^{2}>0.91, p=0.95\right)$, but not with temperature $\left(r^{2}<0.02, p=0.95\right)$, which ranged from $5^{\circ} \mathrm{C}-16^{\circ} \mathrm{C}$. The numbers or species of animals noted from individual cores during sectioning did not correlate with the irrigation constants. Many individuals were likely lost without sieving the remaining sediment after sampling for pore water.

\section{f. Nutrient profiles}

Nutrient pore water profiles were measured at all dates. Data for the February and August cruises are included in Figure 7. Using the bromide-derived irrigation functions we can calculate the irrigation flux and relate it to the diffusive flux along the steep interfacial concentration gradients. Figure 7 depicts for each depth horizon the relative magnitude of the irrigation flux as a percentage of the diffusive flux at the sediment-water interface. The diffusive interface flux is calculated along the steep concentration gradient $\left(\mu \mathrm{M} \mathrm{cm}^{-1}\right)$ using 2-4 data points below the interface and appropriate $D_{s}$ (porosity-corrected by $D_{s}=$ $\left.\phi D_{0}\right)$. 


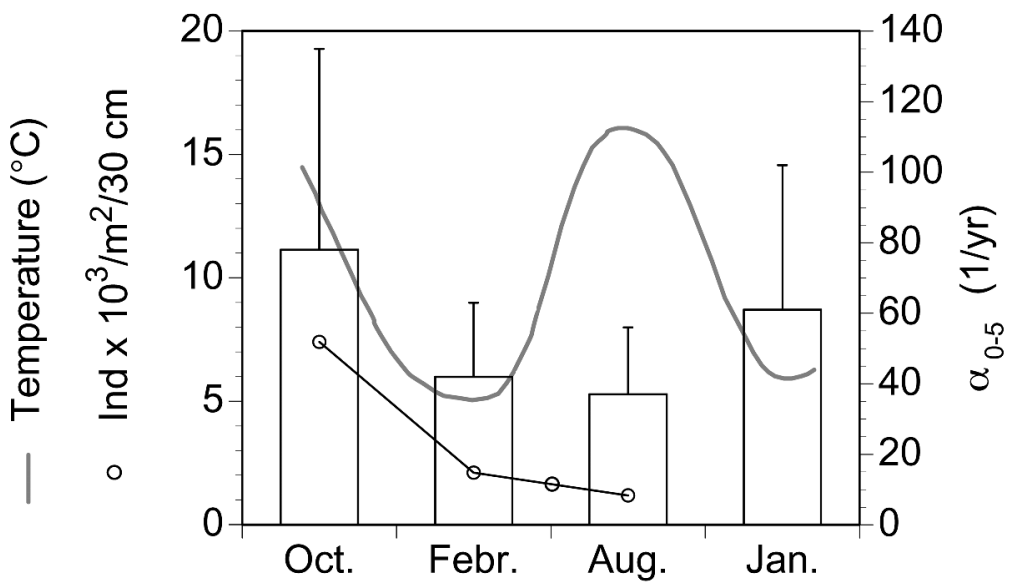

Figure 6. Variation of bottom water temperature including an idealized curve of seasonal variation, abundance of fauna within the upper $15 \mathrm{~cm}$ of the sediment ( $250 \mu \mathrm{m}$ mesh), and average nonlocal irrigation coefficient in the top $5 \mathrm{~cm}$ of the sediment $\left(\alpha_{0_{-5}}\right)$.

In February the average irrigation constant results in an irrigation flux for ammonia of $562 \mu \mathrm{mol} \mathrm{m}{ }^{-2} \mathrm{~d}^{-1}$, ranging from $516-817 \mu \mathrm{mol} \mathrm{m}^{-2} \mathrm{~d}^{-1}$ for the lowest and highest $\alpha$ given in Table 1. The same numbers for silica are $620 \mu \mathrm{mol} \mathrm{m}^{-2} \mathrm{~d}^{-1}$ (range 556$910 \mu \mathrm{mol} \mathrm{m}{ }^{-2} \mathrm{~d}^{-1}$ ) and $67 \mu \mathrm{mol} \mathrm{m}{ }^{-2} \mathrm{~d}^{-1}$ for phosphate (range: 58 to $100 \mu \mathrm{mol} \mathrm{m}{ }^{-2} \mathrm{~d}^{-1}$ ). The same calculation for the August nutrient profiles yields irrigation fluxes of $336 \mu \mathrm{mol} \mathrm{m}{ }^{-2} \mathrm{~d}^{-1}$ for ammonia (range $152-618 \mu \mathrm{mol} \mathrm{m}^{-2} \mathrm{~d}^{-1}$ ), $322 \mu \mathrm{mol} \mathrm{m}{ }^{-2} \mathrm{~d}^{-1}$ (range $146-610 \mu \mathrm{mol} \mathrm{m}^{-2} \mathrm{~d}^{-1}$ ) for silica, and $15 \mu \mathrm{mol} \mathrm{m}{ }^{-2} \mathrm{~d}^{-1}$ for phosphate (range: 7 to $30 \mu \mathrm{mol} \mathrm{m} \mathrm{m}^{-2} \mathrm{~d}^{-1}$ ).

\section{Discussion}

\section{a. Magnitude and range of irrigation}

Alphas calculated in this study are generally of similar magnitude as values published earlier. The irrigation parameters derived from different pore water solutes, and summarized in Table 2, all decline quickly with depth and are highly variable. Two of these studies appear to differ a little from the rest (Schlüter et al., 2000; van Cappellen and Wang, 1996). Van Cappellen and Wang (1996) fit one pair of $\alpha_{0}, \alpha_{1}$ required to conform to a large set of biogeochemical processes, calculating comparatively high $\alpha$. However, even their estimate lies within the range we determined in our study. The values selected from the study by Schlüter et al. (2000) seem to indicate no decline of irrigation from $0-5 \mathrm{~cm}$ to the $5-10 \mathrm{~cm}$ interval. The authors discuss the possibility that lack of behavior of fauna included in the model affects their calculations. Older studies (Christensen et al., 1984; Emerson et al., 1984; Hammond and Fuller, 1979), summarized in Boudreau (1997), show values comparable to ours when the depth interval is taken into account. Reasons for 
Table 3. Fauna retrieved from the upper $15 \mathrm{~cm}$ of the sediment at $54^{\circ} 01^{\prime} \mathrm{N} / 07^{\circ} 49^{\prime} \mathrm{E}$ in the southern North Sea. A total area of $0.75 \mathrm{~m}^{2}$ was sieved through $250 \mu \mathrm{m}$ mesh.

Sampling date:

23.10 .1988

03.02.1989

21.05.1989

22.08.1989

BIVALVIA

Abra alba

68

Abra nitida

Nucula nitida

121

Mya arenariajuv.

Phaxas pellucidus

28

Thyasiraflexuosa

145

Venus fasciata

3

rare/juv. bivalvia

80

CRUSTACEA

Callianassa subterranea

1

Crangon vulgaris

Diastylis rathkei

Pontoporeia affinis

rare/juv. crustacea

ECHINODERMATA

Echinocardium cordatum

Ophiura albida

$64 \quad 8$

rare/juv. echinodermata

GASTROPODA

109

120

0

0

145

168

29

12

1

12

44

152

5

48

5

23

5

17

20

0

0

1

0

3

4

0

24

300

283

220

50

3

2

Natica alderi

Retusa obtusa

rare/juv. gastropoda

OLIGOCHAETA

Oligochaeta spec.

POLYCHAETA

Antoniella sarsi

Chaetopterus variopedatus

0

7

1

0

32

Eulalia viridis

Flabelligera affinis

Lanice conchilega

Nephtys spec.

Ophelia limacina

Owenia fusiformis

Pectinaria koreni

Scoloplos armiger

Spiophanes bombyx

Zeppelina monostyla

rare/juv. polychaeta

other species

Sum
15

12

2

13

12

5

8

0

0

51

87

0

671

3

15

0

0

6

2

1494
31

0

69

0

0

32

0

0

12

0

1

1

1

33

319

1

31
0
69
0
0
32
0
0

2

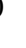

.

.

1

0

7

0

3

0

0

0

0

296

20

16

324

12

0

1

0

1

0

1183 

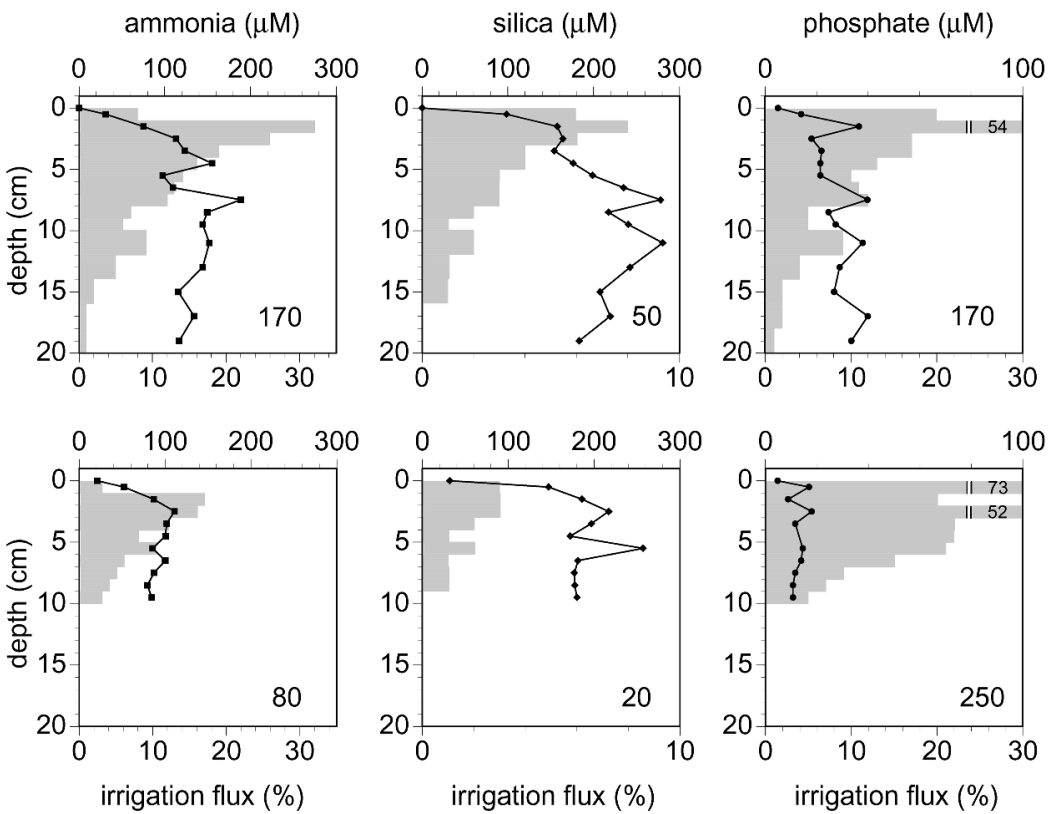

Figure 7. Pore water profiles of $\mathrm{NH}_{4}^{+}, \mathrm{Si}(\mathrm{OH})_{4}$, and $\mathrm{PO}_{4}^{3-}$ with the associated non-local irrigation fluxes. Data are from February (top row) and August (bottom row) with fluxes calculated according to the corresponding irrigation term, $\alpha\left(C_{\mathrm{olw}}-C\right)$ of the diagenetic equation for each sediment layer. Irrigation fluxes (bars; lower abscissae) are expressed as percentage of the diffusive flux supported by the concentration gradient at the sediment-waterinterface, which is set to $100 \%$ and determined from 2-4 concentration data points (dots; upper abscissae). Numbers at the lower right give the sum of irrigation fluxes from each depth equivalent to the total irrigation flux as a percentage of the diffusive flux. Absolute numbers for irrigation fluxes are given in the text.

differences may be found in the use of different solutes for the determination of irrigation parameters and the exponential depth-distribution used in most investigations listed in Table 2 (Meile et al., 2001; Soetaert et al., 1996).

In our general procedure we mixed sediments thoroughly across a horizontal distance of $19 \mathrm{~cm}$. This averaging scale, typically the core diameter, often differs with experimental design and may obscure to some extent the comparison above with data obtained by other researchers, if the sample size does not include sufficient burrows. Whether density of benthic fauna is sufficient to affect all of our sediment may be assessed by the diffusion characteristics around burrows.

For our experiments we estimate the radial half-distance between burrows by assuming simple average diffusion for four days at constant $D_{s}=6 \cdot 10^{-6} \mathrm{~cm}^{2} \mathrm{~s}^{-1}$. The horizontal diffusion distance, $x$, from the burrow interfaces is approximately given by EinsteinSmoluchowsky relation, $x=\left(2 \cdot D_{s} \cdot t\right)^{1 / 2}\left[\left(2 \cdot 6 \cdot 10^{-6} \cdot 4 \cdot 24 \cdot 3600\right)^{1 / 2}=2 \mathrm{~cm}\right]$. Thus, during this period, radial diffusion of tracer ions reaches about $2 \mathrm{~cm}$ horizontally into the 
sediment. Neighboring burrows should be at about this half-distance for the tracer to penetrate, on average, all of the bulk sediment and leave no sediment pore water without tracer. This means that on average a minimum of $22\left\{(9.5 \mathrm{~cm} / 2 \mathrm{~cm})^{2}\right\}$ burrows or irrigating organisms should have been evenly spaced throughout one sediment core. With the abundance of polychaetes and some echinoderms and crustaceans present (Table 3 ) the density of burrowing infauna meets this rough estimate easily. However, wide spacing of burrows, associated with patchy distribution of fauna and the decline of animal abundance with depth, is certainly one source of variability in all of the data presented in Table 2 .

As expected, concentrations measured from sampling exclusively close to burrows yielded unrealistically high $\alpha$. These values also indicate much deeper penetration of the irrigation effect than is calculated from the averaged $\mathrm{Br}^{-}$-concentrations (Fig. 5). The example in Figure 5 demonstrates that values of function $\alpha$ may be exaggerated by a factor $2-3$ by inappropriate sampling. Also this pronounced effect on $\alpha$ is not discernable directly from the tracer distributions (Figs. 3, 5). While the $\alpha$ determined from burrows cannot be interpreted in a meaningful way, burrows are the locations of intense solute exchange also at sediment depths below $16 \mathrm{~cm}$ (Ziebis et al., 1996b).

\section{b. Factors regulating irrigation}

Our results reflect spatial heterogeneity of the benthic macrofauna community composition. The effect associated with the choice of $b$ in (8) is by far too small to explain variations. Sediment cores were randomly sampled from the seafloor in a series of box corer hauls. Within one box core, cores were $25 \mathrm{~cm}$ apart. If taken from repeated box cores, sediment sub-cores were typically on the order of $10 \mathrm{~m}$ apart. At this spatial scale, $0.25-10.0 \mathrm{~m}$, calculated $\alpha_{0-5}$ varies by a factor $>2$ between 'adjacent' cores. Clearly, several samples are required even with our rather large core diameters of $20 \mathrm{~cm}$ diameter. We can demonstrate a worst case scenario by selectively averaging three of the six adjacent cores we obtained in August. Assuming that only 3 cores had been incubated, average $\alpha_{0-5}$ of $24 \pm 20$ and $46 \pm 2(n=3)$ are calculated as the minima and maxima, respectively. These means are not significantly different $(p=0.125)$. Furthermore they are not significantly different from the overall average either $(35 \pm 18 ; n=6)$. Thus, routinely increasing the number of replicate samplings to six cores in order to better constrain $\alpha$ would not have been sufficient in this case. Given the already large size cores of $314 \mathrm{~cm}^{2}$ sediment surface, still higher numbers of replica are not feasible for practical reasons. We cannot explore core-to-core differences in more detail here, because macrofauna was not retrieved from the experimental cores quantitatively. Our results show though, that future efforts should focus on explaining small-scale differences in bioturbation and -irrigation. We conclude that in view of the high variability imposed by fauna (see below), sampling three cores is sufficient.

Irrigation rate constants vary as much among adjacent cores, as they do between seasons. In contrast to many other processes at the sea floor, transport of tracer by bioirrigation did not display a dependency on temperature, though the latter varied between 
$5^{\circ} \mathrm{C}$ and $16^{\circ} \mathrm{C}$ over all seasons (Fig. 3). On the other hand, temperature dependence of microbially mediated processes is to be expected (Graf et al., 1983; Kristensen et al., 1992). Investigating the aerobic respiration of sediments from Aarhus Bay, Thamdrup et al. (1998) measured a rate increase, $Q_{10}$, in the temperature range $0-14^{\circ} \mathrm{C}$. They calculated a weak temperature dependence of area-specific aerobic mineralization with $Q_{10}=1.8$. Westrich and Berner (1988) found that $Q_{10}$ for sulfate reduction rates in Long Island Sound surface sediments were on the order of 2-3 for a comparable temperature range. It seems that irrigation activity is much less temperature-dependent than the processes referred to above. Since bioirrigation, and bioturbation, have a profound impact on early diagenesis, the observed decoupling of temperature and transport intensity probably has a dampening effect on the temperature-dependence of many early diagenetic processes.

The number of animals sieved from box coring correlated with the averaged irrigation constants $\alpha_{0}$ and $\alpha_{1}$ for that sampling occasion. The limited information on fauna present in individual experimental cores, which were not sieved, did not show any relation to the irrigation constants determined for those cores. Martin and Banta (1992) report that their irrigation coefficients correlate roughly with the abundance of the dominant bioturbator Nephtys incisa, but not with any other abundant fauna. It becomes clear from Table 3 that all species, including the active burrowing Nephtys spec., decline in abundance in a similar manner and comparable to the total number of individuals reported in Figure 6. The exceptions to this trend are Lanice conchilega, Callianassa subterranea, Echinocardium cordatum and Ophiura albida. L. conchilega and C. subterranea both construct burrows that can be considered stationary during the course of our experiments, and both species ventilate their burrows (Fig. 8 in Forster and Graf (1995)). E. cordatum and O. albida by way of their errant life style are able to move pore water at depth and at the sediment surface, respectively. Possibly, constant or increasing numbers in one or several of these species counteract the more than 6-fold decrease in total abundance. Whether this is the reason for the comparatively small, 2-fold decrease in $\alpha_{\mathrm{O}-5_{5}}$ (Fig. 6) remains speculation.

Next to the abundance of fauna, behavior is the second most important regulator of nonlocal exchange. This is seen in the animals' response to environmental changes, which have a clear effect on $\alpha$. Interpreting the irrigation activity during experimentally induced hypoxia, Forster et al. (1995) used an effective irrigation coefficient, $K_{\text {bio }}$. Here we recalculated these data and observed a 3 -fold increase in $\alpha$ at all sediment depths, as well as continuation of the intense irrigation during the reoxygenation phase of the experiment. The pattern is the same in the nonlocal modeling used in this contribution and treatment as enhanced diffusive process using $K_{\text {bio }}$ in Forster et al. (1995). During hypoxia (25\% saturation; $67 \mu \mathrm{M} \mathrm{O}_{2}$ ) the benthic community compensated for a lack of oxygen by pumping more overlying water through the sediment. This temporally stronger bioirrigation also reached deeper sediment layers, as seen in Figure 4. The implications of this finding are that small benthic populations under hypoxic stress may be as effective in pore water transport as large communities under fully oxic conditions. This contrasts with the 
interpretation put forward by Schlüter et al. (2000) for their field site, who indicated that increased sedimentation and upward movement of the infauna, owing to oxygen depletion, probably reduced sediment irrigation at depth. It is likely that both duration and strength of oxygen depletion govern the extent to which benthic fauna are able to withstand hypoxic stress through compensation mechanisms, conforming to the conditions, or possibly flight. Predicting increase or decrease of irrigation seems a promising future task.

\section{c. Effects on fluxes}

Pore water gradients influenced by bioirrigation do not at all reflect a simple relation between concentration gradients and diffusive fluxes. This has been demonstrated eloquently by Aller (1980) with his radial diffusion model. Furthermore, an irrigation rate constant determined from a tracer experiment and used to represent non-local exchange does not describe irrigational solute flux for different species of solutes equally well (Aller, 1983; Emerson et al., 1984). Iron and manganese-cycling (Aller, 1980; Thamdrup et al., 1994a,b; van Cappellen and Wang, 1996) as well as sulfide oxidation (Christensen et al., 1984; Fossing et al., 2000) tend to be strongly affected by bioirrigation. On the other hand more complicated assumptions may be needed when applying a nonlocal transport model not to irrigation flux of oxygen (Furukawa et al., 2000), since, owing to the high reactivity and limited penetration of $\mathrm{O}_{2}$ into the sediments, there usually is no average concentration built-up from ventilated burrows at any given depth. Still, transport of $\mathrm{O}_{2}$ along burrows at depth does increase the oxygen uptake of this and other sediments (Fenchel, 1996; Forster and Graf, 1995; Forster et al., 1999; Ziebis et al., 1996a,b).

Making use of the ammonia, silica and phosphate distributions measured at the sampling dates we can calculate the term $\alpha\left(C_{\text {olw }}-C\right)$ for each sediment layer (Fig. 7). This translation of rate constants into real fluxes is a valuable exercise, for irrigation fluxes and diffusive fluxes across the sediment-water interface may be compared.

Depending on the solute, the depth-integrated irrigation fluxes amount to $20-250 \%$ of the diffusive fluxes. Ammonia and silica irrigation fluxes enhance total benthic fluxes more in winter than in summer. The absolute numbers of irrigation flux for ammonia are also higher in winter $\left(562 \mu \mathrm{mol} \mathrm{m} \mathrm{m}^{-2} \mathrm{~d}^{-1}\right)$ than in summer $\left(336 \mu \mathrm{mol} \mathrm{m}^{-2} \mathrm{~d}^{-1}\right)$, while diffusive interfacial fluxes were calculated as 325 and $400 \mu \mathrm{mol} \mathrm{m}^{-2} \mathrm{~d}^{-1}$, respectively. The effect is similar for silica, but the contribution of irrigation is relatively weak owing to strong interfacial diffusive fluxes of 1360 in winter and $2070 \mu \mathrm{mol} \mathrm{Si} \mathrm{m} \mathrm{d}^{-2}$ and summer. Silica-fluxes compare well with those measured by Gehlen et al. (1995) in the Southern Bight of the North Sea.

Strongest relative enhancement is seen in phosphate fluxes. Interfacial gradients support a small diffusive exchange of $8 \mu \mathrm{mol} \mathrm{P} \mathrm{m}{ }^{-2} \mathrm{~d}^{-1}$ in winter and $39 \mu \mathrm{mol} \mathrm{P} \mathrm{m}{ }^{-2} \mathrm{~d}^{-1}$ in summer, while $170 \%$ and $250 \%$ of these values respectively are transported via irrigation. In their approach to quantify global enhancement of benthic phosphorus fluxes, Meile and Van Cappellen (2003) arrived at $\sim 300 \%$ increase in P-flux on shelf and slope sediments due to irrigation. Our data support this view. 
The overall ammonia fluxes thus calculated, [562 $270 \% / 170 \%=] 893 \mu \mathrm{mol} \mathrm{m} \mathrm{m}^{-2} \mathrm{~d}^{-1}$ for February and $[336 \cdot 180 \% / 80 \%=] 756 \mu \mathrm{mol} \mathrm{m}^{-2} \mathrm{~d}^{-1}$ in August, compare well with published data on similar North Sea sediments, e.g. Lohse et al. (1995). An important if not major part of the total solute flux in the diagenetically active surface layer of this shelf sediment is attributed to bioirrigation.

\section{Conclusions}

This study on the intensity of pore water transport yielded results for fluid exchange by bioirrigation in a typical Nucula nitidosa-assemblage of the North Sea. With a temperature range from $5-16^{\circ} \mathrm{C}$ and all of the major fauna components present, $\alpha$-values ranged from 21 to $>250 \mathrm{yr}^{-1}$. While depth penetration was more or less constant at $12-16 \mathrm{~cm}$, the magnitude of the irrigation process varied primarily with the abundance and the pumping behavior of the infauna. Inter-sample variability was as high as seasonal differences. Seasonality or temperature effects on bioirrigation intensity were not visible in this study, indicating that bioirrigation may in fact overlay any seasonally driven temperature effects usually seen in benthic nutrient fluxes.

Acknowledgments. This work was supported by the German Federal Ministry of Education and Research (BMBF), the Max-Planck Society and the Baltic Sea Research Institute. We also wish to acknowledge the important practical help by W. Queisser and M. Teucher, as well as many valuable comments by B. P. Boudreau and three unknown referees.

\section{REFERENCES}

Aller, R. C. 1980. Quantifying solute distributions in the bioturbated zone of marine sediments by defining an average microenvironment. Geochim. Cosmochim. Acta, 44, 1955-1965.

1983. The importance of the diffusion permeability of animal burrow linings in determining marine sediment chemistry. J. Mar. Res., 41, 299-322.

Aller, R. C. and J. Y. Aller. 1992. Meiofauna and solute transport in marine muds. Limnol. Oceanogr., 37, 1018-1033.

Berner, R. A. 1980. Early Diagenesis. A Theoretical Approach, Princeton University Press, Princeton, NJ, $241 \mathrm{pp}$.

Boudreau, B. P. 1984. On the equivalence of nonlocal and radial-diffusion models for porewater irrigation. J. Mar. Res., 42, 731-735.

1997. Diagenetic Models and Their Implementation-Modelling Transport and Reactions in Aquatic Sediments, Springer, Berlin, 414 pp.

1998. Mean mixing depth of sediments: The wherefore and why. Limnol. Oceanogr., 43, $524-526$.

Boudreau, B. P., A. Mucci, B. Sundby, G. W. Luther and N. Silverberg. 1998. Comparative diagenesis at three sites on the Canadian continental margin. J. Mar. Res., 56, 1259-1284.

Brey, T. 1986. Formalin and formaldehyde-depot chemicals: effects on dry weight and ash free dry weight of two marine bivalve species. Meeresforschung, 31, 52-57.

Canfield, D. E., B. B. Jørgensen, H. Fossing, H. Glud, J. Gundersen, N. B. Ramsing, B. Thamdrup, J. W. Hansen, L. P. Nielsen and P. O. J. Hall. 1993. Pathways of organic carbon oxidation in three continental margin sediments. Mar. Geol., 133, 27-40.

Canfield, D. E., B. Thamdrup and J. Würgler Hansen. 1993. The anaerobic degradation of organic 
matter in Danish coastal sediments: Fe reduction, Mn reduction, and sulfate reduction. Geochim. Cosmochim. Acta, 57, 3867-3883.

Chant, L. A. and R. J. Cornett. 1991. Smearing of gravity core profiles in soft sediments. Limnol. Oceanogr., 36, 1492-1498.

Christensen, J. P., A. H. Devol and W. M. Smethie, Jr. 1984. Biological enhancement of solute exchange between sediments and bottom water on the Washington continental shelf. Cont. Shelf Res., 3, 9-23.

Crank, J. and P. Nicholson. 1947. A practical method for numerical evaluation of solutions of partial differential equations of the heat conduction type. Proc. Camb. Soc., 43, 50-67.

Dennis, J. E., D. M. Gay and R. E. Welsch. 1981. An Adaptive Nonlinear Least-squares Algorithm. ACM Transaction on Mathematical Software, 7, 348-368.

Dicke, M. 1986. Vertikale Austauschkoeffizienten und Porenwasserfluß an der Sediment/WasserGrenzfläche. Ph.D. Thesis, Kiel.

Duineveld, G. C. A., A. Künitzer, U. Niermann, P. A. J. deWilde and J. S. Gray. 1991. The macrobenthos of the North Sea. Neth. J. Sea Res., 28, 53-65.

Emerson, S., R. Jahnke and D. Heggie. 1984. Sediment-water exchange in shallow water estuarine sediments. J. Mar. Res., 42, 709-730.

Fenchel, T. 1996. Worm burrows and oxic microniches in marine sediments. 1. Spatial and temporal scales. Mar. Biol., 127, 289-295.

Forster, S., R. N. Glud, J. K. Gundersen and M. Huettel. 1999. In situ study of bromide tracer and oxygen flux in coastal sediments. Estuar. Coast. Shelf Sci., 49, 813-827.

Forster, S. and G. Graf. 1995. Impact of irrigation on oxygen flux into the sediment: intermittent pumping by Callianassa subterranea and 'piston-pumping' by Lanice conchilega. Mar. Biol., $123,335-346$.

Forster, S., G. Graf, J. Kitlar and M. Powilleit. 1995. Effects of bioturbation in oxic and hypoxic conditions: a microcosm experiment with a North Sea sediment community. Mar. Ecol. Prog. Ser., 116, 153-161.

Fossing, H., T. G. Ferdelman and P. Berg. 2000. Sulfate reduction and methane oxidation in continental margin sediments influenced by irrigation (South-East Atlantic off Namibia). Geochim. Cosmochim. Acta, 64, 897-910.

Furukawa, Y., S. J. Bentley, A. M. Shiller, L. L. Dawn and P. vanCappellen. 2000. The role of biologically-enhanced pore water transport in early diagenesis: an example from carbonate sediments in the North Key Harbor, Dry Tortugas National Park, Florida. J. Mar. Res., 58, 943-522.

Gehlen, M., H. Malschaert and W. R. Van Raaphorst. 1995. Spatial and temporal variability of benthic silica fluxes in the southeastern North Sea. Cont. Shelf Res., 15, 1675-1696.

Graf, G., R. Schulz, R. Peinert and L. A. Meyer-Reil. 1983. Benthic response to sedimentation events during autumn to spring at shallow-water station in the western Kiel Bight. 1. Analysis of processes on a community level. Mar. Biol., 77, 235-246.

Grasshoff, K., M. Ehrhardt and K. Kremling. 1983. Methods of Seawater Analysis, Verlag Chemie, Weinheim, $317 \mathrm{pp}$.

Hammond, D. E. and C. Fuller. 1979. The use of Radon-222 to estimate benthic exchange and athmospheric exchange rates in San Francisco Bay, in San Francisco Bay: The Urbanized Estuary, Pacific Division, Amer. Assoc. Advance. Sci., 213-230.

Kremling, K. 1983. Determination of the major constituents, in Methods of Seawater Analysis, K. Grasshoff, M. Ehrhard and K. Kremling, eds, Verlag Chemie, Weinheim.

Kristensen, E., F. Andersen and T. H. Blackburn. 1992. Effects of benthic macrofauna and temperature on degradation of macroalgal detritus: The fate of organic carbon. Limnol. Oceanogr., $37,1404-1419$. 
Li, Y.-H. and S. Gregory. 1974. Diffusion of ions in sea water and in deep-sea sediments. Geochim. Cosmochim. Acta, 38, 703-714.

Lohse, L., J. F. P. Malschaert, C. P. Slomp, W. Helder and W. van Raaphorst. 1995. Sediment-water fluxes of inorganic nitrogen compounds alon the transport route of organic matter in the North Sea. Ophelia, 41, 173-197.

Martin, W. R. and G. T. Banta. 1992. The measurement of sediment irrigation rates: a comparison of the $\mathrm{Br}^{-}$tracer and ${ }^{222} \mathrm{Rn} /{ }^{226} \mathrm{Ra}$ disequilibriumtechniques. J. Mar. Res., 50, 125-154.

Meile, C., C. M. Koretsky and P. van Cappellen. 2001. Quantifying bioirrigation in aquatic sediments: an inverse modeling approach. Limnol. Oceanogr., 46, 164-177.

Meile, C. and P. van Cappellen. 2003. Global estimates of enhanced solute transport in marine sediments. Limnol. Oceanogr., 48, 777-786.

Moré, J. J., B. S. Grabow and K. E. Hillstrom. 1980. User guide for MINIPACK-1, Argonne. National Laboratory Report ANL-80-74, Argonne National Laboratories; Argonne, IL.

Östlund, P. and R. O. Hallberg. 1989. Porewater mixing by microorganisms, monitored by a radiotracer method. Geomicrobiol. J., 7, 253-264.

Press, W. H., S. A. Teukolsky, W. T. Vetterling and B. Flannery. 1992. Numerical Recipes in Fortran. Cambridge University Press, $126 \mathrm{pp}$.

Saager, P. M., J.-P. Sweerts and H. J. Ellermeijer. 1990. A simple pore-water sampler for coarse, sandy sediments of low porosity. Limnol. Oceanogr., 35, 747-751.

Salzwedel, H., E. Rachor and D. Gerdes. 1985. Benthic macrofauna communities in the German Bight. Veröff. Inst. Meeresforsch. Bremerh., 20, 199-267.

Schlüter, M., E. Sauter, H.-P. Hansen and E. Suess. 2000. Seasonal variation of bioirrigation in coastal sediments: modeling of field data. Geochim. Cosmochim. Acta, 64, 821-834.

Soetaert, K., P. M. J. Herman and J. J. Middelburg. 1996. A model of early diagenetic processes from the shelf to abyssal depths. Geochim. Cosmochim. Acta, 60, 1019-1040.

Thamdrup, B., H. Fossing and B. B. Jørgensen. 1994a. Manganese, iron, and sulfur cycling in a coastal marine sediment, Aarhus Bay, Denmark. Geochim. Cosmochim. Acta, 58, 5115-5129.

Thamdrup, B., R. N. Glud and J. Würgler Hansen. 1994b. Manganese oxidation and in situ manganese fluxes from a coastal sediment. Geochim. Cosmochim. Acta, 58, 2563-2570.

Thamdrup, B., J. Würgler Hansen and B. B. Jørgensen. 1998. Temperature dependence of aerobic respiration in a coastal sediment. FEMS Micro. Ecol., 25, 189-200.

Ullman, W. J. and R. C. Aller. 1982. Diffusion coefficients in nearshore marine sediments. Limnol. Oceanogr., 27, 552-556.

van Cappellen, P. and Y. Wang. 1996. Cycling of iron and manganese in surface sediments: A general theory for the coupled transport and reaction of carbon, oxygen, nitrogen, sulfur, iron, and manganese. Am. J. Sci., 296, 197-243.

Weissberg, H. 1963. Effective diffusion coefficients in porous media due to fluctuating flows. J. Appl. Phys., 34, 2636-2639.

Westrich, J. T. and R. A. Berner. 1988. The effect of temperature on rates of sulfate reduction in marine sediments. Geomicrobiol. J., 6, 99-117.

Ziebis, W., S. Forster, M. Huettel and B. B. Jørgensen. 1996b. Complex burrows of the mud shrimp Callianassa truncata and their geochemical impact in the sea-bed. Nature, 382, 619-622.

Ziebis, W., M. Huettel and S. Forster. 1996a. Impact of biogenic sediment topography on oxygen fluxes in permeable seabeds. Mar. Ecol. Progr. Ser., 140, 227-237.

Received: 1 March, 2001; revised: 6 May, 2003. 